\title{
O plano de estudos: um gênero textual acadêmico para pleitear intercâmbio
}

\author{
Emily Caroline da Silva* \\ Eliane Gouvêa Lousada**
}

\begin{abstract}
Resumo
Este artigo insere-se dentro de duas problemáticas atuais e paralelas: por um lado, a da internacionalização das universidades brasileiras e, por outro, a da escrita em meio acadêmico. Com o intuito de contribuir para a expansão de pesquisas focadas na didática de gêneros textuais acadêmicos, como as de Machado, Lousada e Abreu-Tardelli (2004a, 2004b, 2005a, 2007), Motta-Roth e Hendges (2010) e baseado nos pressupostos teóricos do Interacionismo Sociodiscursivo (BRONCKART, 1999, 2006), este artigo visa a: a) propor um modelo didático (SCHNEUWLY, DOLZ, 2004) do gênero plano de estudos acadêmico para pleiteio de intercâmbio; b) a criar uma proposta de sequência didática (SCHNEUWLY, DOLZ, 2004) para alunos universitários, baseada no modelo didático elaborado.
\end{abstract}

Palavras-chave: letramento acadêmico; gênero textual; plano de estudos.

\begin{abstract}
This article focuses on two current and parallel issues: first, the internationalization of Brazilian Universities; secondly, the academic writing. Intending to contribute to the expansion of research related to the teaching of academic text genres, such as the studies of Machado, Lousada and Abreu-Tardelli (2004a, 2004b, 2005a, 2007) or Motta-Roth and Hendges (2010), and based on the Socio-discursive Interactionism (BRONCKART, 1999, 2006), this paper aims: a) to propose a didactic model (SCHNEUWLY, DOLZ, 2004) of the text genre "Application Essay", in order to apply for an exchange program; b) to create a didactic sequence (SCHNEUWLY, DOLZ, 2004), based on this didactic model, to use with students at University.
\end{abstract}

Keywords: Academic Literacy; Text Genre; Application Essay

\section{Introdução}

Duas problemáticas têm se mostrado presentes no ambiente universitário recentemente no Brasil. A primeira delas diz respeito à internacionalização das universidades brasileiras e deveu-se ao crescimento econômico e à maior visibilidade que o país conquistou nos últimos anos, que teve como consequência o fato de que as universidades brasileiras começaram a despontar no cenário mundial. A segunda decorre diretamente da primeira, pois, se os contatos com universidades estrangeiras aumentam, quer seja no nível da pesquisa, do ensino ou mesmo administrativo, torna-se imprescindível que a comunicacão nesses três níveis ocorra em uma língua compartilhada, que raramente é o português.

Para ilustrar o quadro de internacionalização das universidades brasileiras, podemos mencionar que a Universidade de São Paulo (USP), por exemplo, foi a única universidade latino-americana a integrar o ranking internacional das duzentas melhores universidades em 2011 (cf. Times Higher Education World University Rankings 2011-2012 ${ }^{1}$ ), melhorando sua colocação

*Endereço eletrônico: emilycsilva@usp.br

**Endereço eletrônico: elousada@usp.br no ano seguinte, e liderou em primeiro lugar o ranking das universidades latino-americanas no mesmo período, seguida pela Universidade Estadual de Campinas. Outras fontes (como QS World University Rankings $2011^{2}$ e Academic Ranking of World Universities $2011^{3}$ ) confirmam as colocações semelhantes para as universidades brasileiras. Já em 2013, o QS World University Rankings by Subject ${ }^{4}$, elaborado pela Quacquarelli Symonds, classificou 29 áreas de concentração da USP, do total das 30 avaliadas, entre as melhores do mundo. A USP foi classificada entre as 100 melhores do mundo em 26 áreas de concentração.

A internacionalização das universidades concretizou-se também como uma das metas do governo federal. Visando a aprimorar esse quadro e garantir a visibilidade do país, o governo federal lançou em 2011 o programa Ciências Sem Fronteiras, cujos objetivos são: investir na formação de pessoal altamente qualificado nas competências e habilidades necessárias para o avanço da sociedade do conhecimento; aumentar a presença de pesquisadores e estudantes de vários níveis em instituições de excelência no exterior; promover a inserção internacional das instituições 
brasileiras pela abertura de oportunidades semelhantes para cientistas e estudantes estrangeiros; ampliar o conhecimento inovador de pessoal das indústrias tecnológicas; atrair jovens talentos científicos e investigadores altamente qualificados para trabalhar no Brasil. Para tanto, o programa cumprirá as metas de 101.000 bolsas de estudos, no Brasil e no exterior, entre os setores de graduação sanduíche, desenvolvimento tecnológico e inovação no exterior, atração de jovens talentos para o Brasil, pesquisadores visitantes para o Brasil, doutorado pleno, doutorado sanduíche e pósdoutorado 5 .

Por um lado, o dos estudantes, tal programa governamental reflete o interesse público em garantir a estes a oportunidade de formação em centros de excelência no exterior para a obtenção de pessoal qualificado no ramo das ciências. Por outro lado, o dos professores, o programa assegura tanto a vinda de pesquisadores visitantes ao Brasil, quanto o oferecimento de bolsas de doutorado e pósdoutorado a pesquisadores brasileiros nas diversas áreas da ciência, refletindo a magnitude do investimento focado na internacionalização das universidades brasileiras.

$\mathrm{Na}$ esteira do programa Ciências sem Fronteiras, algumas universidades lançaram programas de incentivo semelhantes, como é o caso da Bolsa Mérito Acadêmico, da Universidade de São Paulo, através da qual estudantes de graduação não só da área de Ciências, mas de todas as áreas do conhecimento, podem se candidatar para cursar uma parte de seu currículo em uma universidade conveniada no exterior.

Isso nos leva à segunda preocupação, que diz respeito à participação dos alunos, que partem através dos programas de intercâmbio, nas práticas sociais que envolvem a vida acadêmica. Depois de serem escolhidos, eles têm que se adaptar às exigências de avaliação da nova universidade e isso requer o desenvolvimento de práticas linguageiras para às quais eles não foram necessariamente preparados. Porém, antes mesmo de serem escolhidos, o uso da linguagem acadêmica é necessário pois, para participar desses programas, é preciso se candidatar, passar por uma seleção e classificação. Cada programa conta com suas exigências e critérios próprios explicitados nas aberturas de chamadas e editais, entretanto não é raro que se exija, além dos comprovantes e documentos do desempenho acadêmico, um plano de estudos ou uma carta de motivação em que o aluno explicite seus interesses acadêmicos no programa e suas consequências para uma futura inserção profissional na área escolhida.

O plano de estudos ou a carta de motivação sendo um dos critérios para ser selecionado, é importante que a escrita desse documento seja eficaz sobre o destinatário e o convença a selecionar o aluno em questão. Em caso de um possível empate de critérios, os jurados apelariam para esse documento a fim de selecionar o aluno mais adequado, que tem um projeto de estudos mais definido e que mostre como sua formação no exterior poderá se reverter em pesquisas no Brasil.

De maneira análoga, para que os alunos tenham um bom desempenho em aulas e pesquisas na universidade estrangeira, é fundamental que eles consigam evidenciar os resultados obtidos através de relatórios, artigos, trabalhos acadêmicos, seminários, dentre outros, realizados na língua da universidade escolhida. Assim, não basta somente ter um bom desempenho ou obter um resultado, é preciso apresentá-lo da melhor maneira possível à comunidade científica. Daí a preocupação crescente com o letramento acadêmico ${ }^{6}$, que se traduz em inúmeras iniciativas presentes nas universidades para auxiliar a escrita de textos acadêmicos, tanto em português quanto em outras línguas, como é o caso do Laboratório de Letramento Acadêmico ${ }^{7}$, que funciona na Faculdade de Filosofia, Letras e Ciências Humanas, é coordenado pelas Profas. Dras. Marília Ferreira e Eliane G. Lousada e fornece ajuda aos alunos que precisam se expressar em inglês ou francês.

Pensando ainda nas duas problemáticas apontadas, uma vez que o aluno consiga se inscrever em um programa no exterior, como garantir que ele seja capaz de acompanhar as aulas e as formas de estudo em uma comunidade científica de língua estrangeira? É para essa questão que alguns pesquisadores têm se voltado, pensando no letramento acadêmico também em língua estrangeira $^{8}$ (LOUSADA, 2009; LOUSADA, ROCHA e GUIMARÃES-SANTOS, no prelo).

Partindo, então, dessas questões, o objetivo do presente artigo é primeiramente contribuir para a expansão de pesquisas focadas na didática de gêneros textuais acadêmicos como as de Machado, Lousada e Abreu-Tardelli (2004a, 2004b, 2005a, 2005b, 2007) ou Motta-Roth e Hendges (2010), através da elaboração do modelo didático (SCHNEUWLY, DOLZ, 2004) do gênero plano de estudos acadêmico para pleiteio de intercâmbio e, a 
partir dele, uma proposta de sequência didática para alunos universitários. Com esse estudo, é também nossa intenção estabelecer um diálogo entre as pesquisas acadêmicas e as práticas profissionais ligadas à formação de estudantes que buscam pleitear intercâmbios. Nesse sentido, sabemos que há uma carência de estudos sobre este gênero em particular e que, muitas vezes, professores e alunos têm dúvidas quanto à escrita de planos de estudos, o que traz dificuldades para os professores que buscam ensinar a produzi-los.

Antes de iniciarmos propriamente nosso estudo, parece-nos importante ressaltar que estamos considerando o plano de estudos como um gênero pertencente à esfera acadêmica, visto que ele é nomeado como tal e aparece nas instruções oficiais sobre intercâmbio acadêmico, com essa designação, ao menos no contexto da USP. Portanto, julgamos pertinente considerá-lo como um dos gêneros que circulam na esfera acadêmica, ao lado de outros, como veremos mais à frente.

Feita essa breve introdução sobre o tema e explicitados nossos objetivos, apontaremos, a seguir, o quadro teórico das pesquisas sobre gêneros textuais e letramento acadêmico no qual nos baseamos; em seguida, descreveremos a metodologia de realização do modelo didático; dando continuidade, apresentaremos o modelo didático; e, finalmente, mostraremos uma sequência didática para alunos universitários, seguida das considerações finais. Esperamos, assim, que nosso artigo possa contribuir não somente para o avanço de estudos teóricos na área, mas também para as práticas didáticas de letramento acadêmico.

\section{Pressupostos teóricos}

Para desenvolver nosso estudo, baseamonos no Interacionismo Sociodiscursivo, tal como proposto por Bronckart (1999, 2006 e 2008) e por outros pesquisadores de Genebra, como Schneuwly e Dolz (2004), e do Brasil, como Machado e Cristovão (2009), Cristovão (2008), Lousada (2009, 2010), Nascimento (2009), Bueno (2011), entre outros. No entanto, como sabemos, a perspectiva que adotamos não é a única que se dedica aos estudos dos gêneros textuais, sobretudo em se tratando da esfera acadêmica e da produção escrita na universidade, campo em que inúmeras outras pesquisas já foram desenvolvidas, especialmente no que diz respeito ao inglês como segunda língua. Segundo aponta Araújo (2004), os estudos sobre gêneros textuais ganharam grande destaque no Brasil, interessando não somente linguistas, mas críticos literários, analistas do discurso, tradutores, professores de línguas, profissionais da comunicação, dentre outros. Buscando mapear quais correntes foram desenvolvidas no Brasil, Araújo realiza um levantamento de 241 textos científicos nacionais nas áreas de linguística e linguística aplicada (artigos em periódicos; anais de congressos nacionais; teses e dissertações de diferentes programas; livros de análise do discurso e gêneros textuais) e classifica as publicações em perspectivas teóricas, evidenciando a quantidade de publicações por linha. Os resultados apontam que $20,7 \%$ das publicações se filiam à perspectiva Sociorretórica (Swales, Bhatia); 36,9\% à Sociointeracionista (Bakhtin, Bronckart, Dolz \& Schneuwly); 6,22\% à Sistêmico-funcional (Halliday \& Hasan, Martín); 5,39\% à Análise crítica do discurso (Fairclough, Kress); 6,63\% à Linha francesa (Adam, Maingueneau, Charaudeau, Pechêux); e $24 \%$ a uma combinação entre tais linhas. Esse estudo nos parece importante, pois aponta a pertinência da abordagem que adotamos para desenvolver pesquisas no contexto brasileiro.

Entretanto, nossa opção em adotar esse quadro teórico, em meio a inúmeras outras linhas, explica-se por razões que não são apenas quantitativas. $\mathrm{Na}$ verdade, a vertente teórica que adotamos tem as seguintes características que justificam nossa escolha: i) tem sua origem na suíça francófona e, portanto, tem pesquisas que emergem de contextos francófonos, trabalhando com análises de textos em francês, o que é apropriado para nosso estudo; ii) desenvolveu um procedimento não apenas de análise de textos, mas também de reflexão didática sobre $\mathrm{o}$ ensino de produção textual, o que justifica seu uso em pesquisas que desejam ir além do nível analítico, interessando-se por questões práticas de ensino, como é nosso caso; iii) está ancorada no interacionismo social e sobretudo na obra de Vigotski (1997), tendo, portanto, uma compreensão do papel da língua enquanto instrumento psicológico 9 (FRIEDRICH, 2012) que atua nos processos psíquicos das pessoas e interfere no desenvolvimento, o que justifica que acreditemos que o trabalho com os textos acadêmicos, em processos de mediação educativa, possa contribuir para a apropriação de maneiras de dizer pelos alunos, mas, paralelamente, para seu desenvolvimento.

Baseado nos estudos de Vigotski (1997, 
2004), além de Volochinov (1929), o Interacionismo Sociodiscursivo (BRONCKART, 1999, 2006, 2008), quadro teórico em que nos apoiamos, desenvolve pesquisas teóricas e empíricas, estudando o papel fundador da linguagem no desenvolvimento humano. Esse quadro se insere no programa mais amplo do interacionismo social, posicionamento epistemológico para as várias disciplinas das Ciências Humanas, que ressalta a importância do social como fonte do desenvolvimento do funcionamento psíquico. Assim, é através da atividade social, realizada pela mediação da linguagem, que se materializam os diferentes gêneros e é por meio deles que o homem age no mundo. Bronckart (2006, p. 139) define, então, o texto como o correspondente empírico de uma ação de linguagem. Porém, se o texto veicula uma mensagem linguística, ele não é uma unidade linguística, pois suas condições de abertura e de fechamento não dependem do linguístico, pois são determinadas pela ação que o gerou. É nesse sentido que Bronckart (2004) emprega o termo gênero de textos (ou textuais), ao invés de discursivos, pois, para ele, os gêneros só existem pela materialidade dos textos, que se organizam em gêneros. Para Bronckart (2006, p. 143), qualquer texto implica escolhas relativas à seleção e à combinação dos mecanismos estruturantes dos textos, das operações cognitivas que deram origem a ele e de suas modalidades de realização linguística. Sendo assim, os gêneros textuais são produtos das diferentes escolhas linguageiras que deram origem ao texto e que emergem da necessidade de adaptação dos textos às formações sociais de linguagem, para que sejam adaptados às atividades que comentam, ao meio comunicativo, ao contexto sócio-histórico (Bronckart, 2004, p. 144). Além disso, o autor reserva o termo discurso para uma das categorias de análise, os tipos de discurso, que serão apresentados mais à frente.

Schneuwly (2004) define "gênero textual" 10 levando em conta três elementos fundamentais, a saber, os parâmetros de orientação para uma ação discursiva (como finalidade, destinatários, conteúdo); o conjunto possível de gêneros dentro de uma determinada esfera ou de um determinado lugar social; e suas características intrínsecas, conteúdo, estrutura composicional e estilo.

Nessa mesma perspectiva, porém pensando do ponto de vista didático, Schneuwly e Dolz (2004) consideram os gêneros textuais como ferramentas para o ensino, pois, quando apropriados pelos aprendizes, os gêneros tornam possíveis suas ações (individuais) e atividades (coletivas) no mundo. É o duplo papel do gênero no ensino, o de objeto a ser ensinado e de instrumento de trabalho, que lhe confere a característica de "megainstrumento", segundo os mesmos autores.

Pensando, então, em como se ensinar o gênero, os autores ressaltam que, das práticas de linguagem que circulam na sociedade aos objetos de ensino que se estabelecem no currículo escolar, é preciso haver um trabalho de didatização ou de "transposição didática" (CHEVALLARD, 1985). Nesse sentido, para se comunicar e agir por meio da linguagem também é preciso que essas formas de comunicação e gêneros sejam desenvolvidos de maneira didática. Pensando na aprendizagem de aspectos relacionados à linguagem, Schnewly e Dolz (1999) chamam de "capacidades de linguagem" as capacidades do sujeito de se adaptar às características do contexo e do referente (capacidade de ação); de mobilizar modelos discursivos (capacidades discursivas); e de dominar as operações psicolinguísticas e unidades linguístico-discursivas (capacidades linguísticodiscursivas).

No caso específico do trabalho com gêneros para o desenvolvimento das capacidades de linguagem, propõe-se o levantamento das características ensináveis do gênero a fim de elaborar um modelo didático (DE PIETRO, SCHNEUWLY, 2006; SCHNEUWLY, 2006; SCHNEUWLY, DOLZ, 2004) e posteriormente, uma sequência didática (DOLZ; SCHNEUWLY, 1998; SCHNEUWLY; DOLZ, 1997).

Para Schneuwly e Dolz (2004, p.82-84), sequência didática é "um conjunto de atividades escolares organizadas, de maneira sistemática, em torno de um gênero textual oral ou escrito", que "tem a finalidade de ajudar o aluno a dominar um gênero de texto, permitindo-lhe, assim, escrever ou falar de uma maneira mais adequada numa dada situação de comunicação" e "serve para dar acesso aos alunos a práticas de linguagem novas ou dificilmente domináveis". A sequência didática se organiza da seguinte maneira: a) há primeiramente a apresentação da situação de comunicação na qual o gênero escolhido circula e é produzido; b) após essa apresentação os alunos realizam uma produção inicial desse gênero, etapa fundamental para identificar as capacidades de linguagem já adquiridas e ajustar os conteúdos a serem 
trabalhados a partir das dificuldades reais dos alunos; c) as dificuldades identificadas serão trabalhadas de maneira sistemática, aprofundada e progressiva nos módulos (também chamados de aulas ou oficinas), constituídos de atividades e exercícios que fornecerão instrumentos necessários à produção do gênero; e finalmente, d) há uma produção final, em que o aluno será levado a mobilizar as capacidades de linguagem trabalhadas e que poderá indicar os progressos alcançados se comparado à produção inicial.

Para Bronckart (2010, p.172):

A finalidade geral das sequências é o domínio, na produção e na recepção, dos gêneros de textos, na medida em que eles se constituem como instrumentos de adaptação e de participação na vida social/comunicativa. Para atingir esse objetivo, dado que a arquitetura de qualquer texto é altamente complexa, é necessário elaborar um modelo didático do gênero escolhido como objeto de ensino. Esse modelo reúne os conhecimentos teóricos disponiveis sobre esse gênero, seleciona-os e os transpõe, isto é, adaptaos às propriedades do sistema didático envolvido (e, principalmente, ao suposto estado dos saberes e do saber-fazer dos alunos e dos professores).

Na esfera acadêmica, a produção de gêneros textuais relacionados a essa esfera são consideradas práticas linguageiras comuns por seus enunciadores. Pesquisadores, ou aprendizes de pesquisador, sabem que têm que elaborar teses, monografias, seminários, resumos, projetos de pesquisa. Entretanto não podemos afirmar o mesmo das práticas de ensino desses gêneros. Embora se espere que os pesquisadores e futuros pesquisadores expressem-se por meio dos gêneros acadêmicos, sabemos que os gêneros necessários no ambiente universitário são pouco ensinados. Não é raro novos alunos terem dificuldades em se apropriar e produzir esses gêneros, que, até sua entrada nessa esfera, não lhe eram familiares. Estudos têm mostrado que o letramento acadêmico, isto é, a prática de leitura e produção desses gêneros, tornase condição indispensável para inserção de alunos ingressantes na comunidade científica (MOTTAROTH, HENDGES, 2010; MACHADO, LOUSADA, ABREU-TARDELLI, 2004a, 2004b, 2005a, 2005b, 2007).

Além dos gêneros acadêmicos, Swales (1996) chama a atenção para os chamados "gêneros ocultos" (occluded genres), que operam por trás da cena dos gêneros acadêmicos. Para se produzir, por exemplo, um artigo de pesquisa, o estudante deverá mobilizar outros gêneros, como o abstract, carta ou email para submissão de artigo, cartas ou emails relacionados à revisão e à avaliação do artigo, dentre outros. Nesse sentido, podemos contextualizar as noções e conceitos acima explanados ao nosso objeto de estudo: para realizar a ação de pleitear uma bolsa de intercâmbio acadêmico, os candidatos se valem de gêneros textuais, como o formulário, a entrevista etc. Sendo assim, e considerando o plano de estudos como determinante da escolha dos canditatos a intercâmbio, esses gêneros poderiam ser considerados gêneros ocultos da esfera acadêmica.

Assim, para abordar nosso objeto, o gênero plano de estudos, em toda sua complexidade, estudá-lo e compreendê-lo em sua esfera de produção e circulação a partir dos pressupostos teóricos que apresentamos, realizamos uma análise de textos segundo os procedimentos metodológicos que apresentaremos a seguir.

\section{Procedimentos metodológicos}

No intuito de criar um modelo didático do gênero plano de estudos para pleiteio de intercâmbio acadêmico, baseamo-nos nos elementos que guiam a elaboração de um modelo didático (DE PIETRO, SCHNEUWLY, 2006; SCHNEUWLY, DOLZ, 2004) e no modelo de análise de textos proposto por Bronckart $(1999,2006)$.

Uma das razões pelas quais as características dos planos de estudos são desconhecidas é o fato de esse texto não circular publicamente, pois são textos escritos por alunos e endereçados aos comitês de avaliação dos departamentos universitários. Além disso, por haver certa concorrência entre os alunos, não são textos que se encontram facilmente circulando na internet, por exemplo.

Sendo assim, com a intenção de obter um corpus para o presente estudo, entramos em contato com uma pequena amostra de alunos de graduação da área de humanidades (Faculdade de Filosofia, Letras e Ciências Humanas) da Universidade de São Paulo da faculdade em que haviam pleiteado intercâmbio, solicitando uma cópia de seus planos 
de estudos para a realização de um estudo sobre o gênero.

Dessa forma, nosso corpus foi composto de dezessete planos de estudos realizados e submetidos nos anos de 2012 e 2013 por alunos da área de humanas, que pleitearam bolsas de estudos em universidades francesas pelo Programa Bolsas Mérito Acadêmico. Dez desses textos estavam em língua portuguesa e sete em língua francesa. Sendo assim, desse corpus inicial, optamos por analisar, no presente artigo, somente os textos em língua portuguesa $^{11}$.

Analisamos cada um dos textos segundo as categorias de análise de Bronckart (1999), sintetizadas no esquema abaixo (FEITOZA, 2012) e detalhadas a seguir.

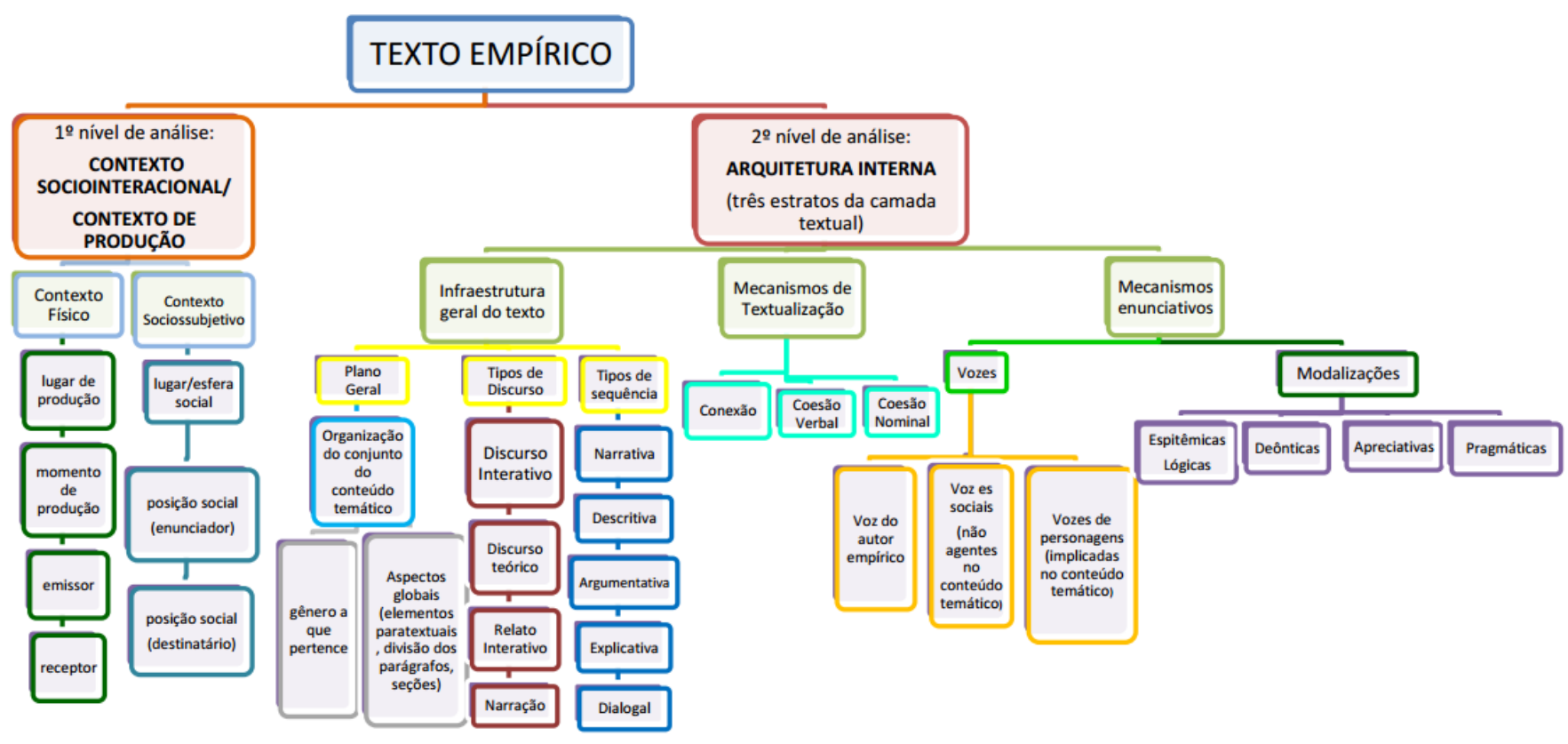

Baseando-nos no modelo de análise de textos de Bronckart (1999, 2006, 2010), podemos elencar as dimensões ensináveis de um determinado gênero segundo os níveis de análise detalhados em seguida e que compõem, segundo o autor, a arquitetura textual. Porém, antes de qualquer análise linguístico-discursiva, temos que estudar o contexto de produção, no qual se pode observar as características do contexto físico, isto é, o emissor, o receptor, qual o momento e o lugar físico de produção do texto; e sobretudo as características do contexto sociossubjetivo, ou seja, qual posição tem o enunciador, o destinatário, com que objetivo produz o texto e que lugar social ocupa. Compreender o contexto de produção e suas variáveis é um passo crucial para escolher e empregar o gênero adequadamente, pois um mesmo sujeito pode assumir diferentes papeis enquanto enunciador, dependendo do lugar social que ocupa ou de seu objetivo.

A arquitetura textual é composta, segundo Bronckart (1999, 2006), de três estratos, ou camadas: a infraestrutura geral do texto, os mecanismos de textualização e os mecanismos enunciativos.

A infraestrutura geral abarca os aspectos discursivos do texto: seu conteúdo temático, as sequências e os tipos de discurso. O conteúdo temático refere-se ao próprio conteúdo do texto, às informações contidas nele, ou seja aos temas escolhidos pelo produtor do texto. As sequências são os segmentos narrativos, argumentativos, explicativos, descritivos, injuntivos e dialogais, que podem, ou não, estar presentes nos textos. Já os tipos de discurso constituem uma noção mais complexa, que leva em conta a implicação ou autonomia do enunciador em relação ao ato de produção do texto e, além disso, a conjunção ou disjunção do mundo discursivo, isto é, se ele se refere ao mundo conjunto e presente à situação de produção ou a um mundo anterior ou posterior, por exemplo. Enquanto as sequências são elementos que podem ou não aparecer nos textos, os tipos de discurso estão sempre presentes. O quadro abaixo, 
proposto por Bronckart (1999), explica como funcionam os tipos de discurso em relação à autonomia e à implicação na situação de produção, e em relação à coordenadas gerais dos mundos (conjunção ou disjunção).

\begin{tabular}{|c|c|c|c|}
\hline & & \multicolumn{2}{|c|}{ Coordenadas gerais dos mundos } \\
\hline & & Conjunção & Disjunção \\
\hline & & EXPOR & NARRAR \\
\hline \multirow{2}{*}{$\begin{array}{l}\text { Relação ao ato } \\
\text { de produção }\end{array}$} & Implicação & Discurso interativo & Relato interativo \\
\hline & Autonomia & Discurso teórico & Narração \\
\hline
\end{tabular}

Já os mecanismos de textualização e os mecanismos enunciativos referem-se aos aspectos linguístico-discursivos, que asseguram a coerência temática e pragmática (ou responsabilização enunciativa) do texto. Cada um desses níveis serviu de categoria de análise para os textos coletados, entretanto, apresentaremos, no presente artigo, apenas as categorias que se mostraram mais relevantes do ponto de vista didático, ou seja, do ensino desse gênero textual.

Após a construção do modelo didático seguindo as categorias acima explanadas, elaboramos a sequência didática tal como mencionamos anteriormente. Para elaborá-la, baseamo-nos nos estudos de Schneuwly e Dolz (2004), que sugerem partir da apresentação da situação de produção, seguida de uma produção inicial do gênero textual em questão. Em seguida, os mesmos autores propõem analisar os conhecimentos prévios dos alunos e as lacunas a serem trabalhadas. Com isso, o intuito é de escolher os elementos do gênero a serem trabalhados, elaborando assim um número de módulos (ou aulas) com atividades didáticas, tantos quantos forem necessários. Finalmente, os mesmos autores sugerem pedir uma produção final do gênero, verificando se os elementos trabalhados foram apropriados pelos alunos e se há um desenvolvimento em relação à produção inicial. Passemos, então, para a apresentação do modelo didático que elaboramos e da sequência didática para ensinar o gênero plano de estudos.

\section{Um modelo didático do plano de estudos}

Como apontamos na Introdução deste artigo, o modelo didático do plano de estudos foi elaborado a partir da: a) análise de dez planos de estudos, redigidos em português por alunos da USP da área de Humanas que se candidataram à Bolsa de Mérito Acadêmico e que a obtiveram; b) consulta a sites da USP que detalham o que é esperado desse documento. Para melhor compreendermos como eram os planos de estudos analisados, é importante salientar que os planos de estudos aos quais tivemos acesso passaram por uma ou duas correções de professores e revisão dos alunos, pois umas das exigências contidas nos editais é que um docente da área valide as informações contidas naquele plano, assinando-o. A escolha desses planos de estudo deu-se pelo fato de termos privilegiado os planos de alunos que obtiveram a bolsa de estudos, logo, seus planos de estudos eram particularmente bem elaborados. Nesse sentido, o modelo didático que estamos propondo adequa-se à proposta dos pesquisadores genebrinos, já que parte de exemplares que contém as características prototípicas do gênero e pode, de certa forma, contribuir para o trabalho de professores, evidenciando características discursivas e linguístico-discursivas básicas do gênero.

O contexto de produção dos planos de estudos que coletamos e analisamos retoma o histórico que apresentamos na introdução deste artigo. Dentro das iniciativas de internacionalização nacionais, a Universidade de São Paulo, por meio da Pró-reitoria de Relações Internacionais, lançou o Programa Bolsa Mérito Acadêmico, cujo objetivo era possibilitar aos alunos regularmente matriculados na USP a realização de atividades acadêmicas no exterior (cursar disciplinas e realizar estágio), durante um semestre, em centros de excelência, como aponta o edital:

As Instituições de destino dos candidatos devem ser preferencialmente aquelas classificadas entre as primeiras 350 colocações em um dos rankings QS, THE e 
Shangai JiaoTong University, e deverão ter convênio de cooperação acadêmica com a USP ou com a Unidade, firmados nos últimos 10 anos. (Edital 1/2012 $2^{12}$ )

Como requisitos para a seleção no programa, os candidatos devem a) apresentar bom desempenho acadêmico; b) ter acumulado no mínimo $20 \%$ e no máximo $80 \%$ dos créditos do curso; c) apresentar no ato da inscrição um plano de estudos, preparado e avalizado por um professor de sua Unidade e validado pela Comissão de Graduação; d) ter proficiência na língua exigida pela Instituição de destino no exterior. Além disso, atividades de Iniciação Científica são levadas em conta, caso o candidato a tivesse realizado. Esses requisitos deveriam ser apresentados sob forma de documentos submetidos em uma plataforma online.

Os candidatos aprovados na seleção recebem uma bolsa com a duração de seis meses, contemplada em até seis mensalidades, mais um adicional de despesas de instalação e despesas pessoais (equivalente ao valor de uma mensalidade), seguro-saúde, passagem aérea de ida e volta e, excepcionalmente, taxas acadêmicas em valores a serem definidos conforme o caso. No caso de dupla diplomação, a duração da bolsa poderia se estender por até 18 meses.

Retomando as categorias de análise, temos como enunciadores os alunos de graduação, que se colocam como alunos de excelente desempenho acadêmico, interessados em realizar um intercâmbio para aprimorar sua formação.

Como destinatário, temos, em primeiro plano, o professor que a carta, endossando as informações ali contidas, em segundo plano, a comissão de avaliação situada na Unidade e, em última instância, na Pró-reitoria de Relações Internacionais que pode ser composta de funcionários e professores da universidade, tendo a função de selecionar e classificar os candidatos de acordo com os critérios pré-estabelecidos.

O lugar social de onde os candidatos falam encontra-se na esfera acadêmica e seu objetivo com o plano de estudos é o de construir uma imagem positiva do enunciador, apresentando a relação das atividades que serão realizadas na universidade de destino, mas também suas qualidades acadêmicas, a fim de convencer o destinatário de que o enunciador daquele texto é merecedor de uma boa classificação e, consequentemente, da bolsa.

$\mathrm{O}$ contexto de produção pode revelar muitos aspectos sutis das situações de comunicação. Um fato interessante, ao investigarmos mais sobre o destinatário do texto, foi que identificamos os seguintes objetivos do departamento de Relações Internacionais da universidade:

- Apoiar os escritórios de Relações Internacionais locais das unidades de ensino e de pesquisa da instituição em suas atividades de internacionalização;

- Oferecer oportunidades de mobilidade à comunidade USP;

- Fomentar a cooperação acadêmica internacional;

- Selecionar, preparar e divulgar informação sobre programas e iniciativas de cooperação internacional;

- Manter articulação com o Ministério das Relações Exteriores do Brasil, bem como embaixadas, consulados, organizações e instituições internacionais;

- Promover ativamente ações com o objetivo de dar maior visibilidade à USP no cenário internacional. (VRERI $U S P)^{13}$

Observe-se que, dentre as iniciativas em se promover a mobilidade internacional dos estudantes, está a contrapartida, obter maior visibilidade para a própria universidade, o que corrobora as metas governamentais mencionadas na Introdução.

Se, por um lado, a maioria dos documentos exigidos são gêneros conhecidos dos alunos, elaborados por outras pessoas e de fácil acesso (histórico escolar; certificado de proficiência), por outro, o plano de estudos/atividades constitui uma incógnita para muitos. Nossa afirmação pode ser comprovada pela seção de perguntas frequentes (FAQ) da Comissão de Cooperação Internacional da USP, que traz como quarta pergunta: "Há modelo de plano de atividades/estudos?", e como resposta: "Os alunos devem buscar essa informação na Unidade.".

Não solucionando a dúvida, um "modelo" do plano de estudos foi disponibilizado no site. Entretanto não se tratava de um exemplar do gênero plano de estudos, mas sim de um exemplo de layout do texto, contendo a seguinte orientação:

Resuma o seu plano de estudos, justificando 
o seu interesse neste programa, além de destacar o nome das disciplinas $e$ as respectivas cargas horárias. Lembre-se que deverá entregar este documento (em Português) no ato da sua inscrição na VRERI, devidamente assinado e carimbado. Sendo aprovado no edital, deverá entregar, também, este documento na língua da Instituição de Ensino de destino, assinado e carimbado.

Passemos aos elementos característicos da infraestrutura geral do plano de estudos. Nos exemplares analisados, encontramos os seguintes conteúdos temáticos:

- cabeçalho, local e data, logotipo da universidade, encontrados em alguns exemplares de textos;

- apresentação acadêmica sucinta (curso, semestre, experiência com pesquisa, atuação profissional na área);

- explicitação do interesse pelo intercâmbio e argumentos que o justificam (contribuição à formação, à pesquisa, experiência linguística, cultural etc.);

- indicação das disciplinas escolhidas e justificativa (sob a forma de listas, tópicos, quadros ou texto);

- retomada das contribuições do intercâmbio para a formação e a contrapartida para a instituição ou para o avanço do conhecimento científico;

- nome e assinatura do aluno e do professor responsável; carimbo do professor ou do departamento.

Observamos que esses conteúdos respondem com sucesso às orientações indicadas no layout, mas trazem outros elementos característicos que não foram necessariamente mencionados ou pedidos.

Com relação aos tipos de sequência empregados, encontramos uma predominância da sequência argumentativa e, em alguns trechos pontuais, sequências narrativas em grau zero - ou script - para relatar as ações realizadas durante a formação. Já para os tipos de discurso, verificamos que sempre há implicação do enunciador, materializada nas diversas marcas de primeira pessoa. Sobre as coordenadas dos mundos discursivos, aparecem o expor, quando se trata de argumentar, explicar ou justificar, e também o narrar, quando há o relato referindo-se às atividades acadêmicas já realizadas, ou às atividades a serem concretizadas na universidade de destino. Dessa forma, encontramos o discurso interativo (expor implicado conjunto) e o relato interativo (narrar implicado conjunto).

A coesão verbal se dá pela concordância entre os tempos verbais empregados no texto, os quais descreveremos seguindo os conteúdos temáticos apresentados. Para a apresentação do percurso acadêmico, foram empregados verbos no pretérito perfeito do indicativo ("teve início meu projeto", "apresentei-me em um colóquio") ou o presente do indicativo para atividades em curso. Para a justificativa do interesse pelo intercâmbio, foi utilizado majoritariamente o presente do indicativo ("meus interesses concentram-se", "a escolha pela França deve-se", "a escolha pela Universidade de Rennes respeita meus objetivos"). Para a descrição das atividades a serem cursadas, foram empregados o futuro do presente e o futuro do pretérito ("no qual eu terei a possibilidade de aperfeiçoar meus conhecimentos linguísticos", "tais disciplinas me proporcionariam um estudo mais aprofundado"). Para a retomada das contribuições do intercâmbio, foram utilizados o futuro do presente e futuro do pretérito ("o que ampliará meus conhecimentos linguísticos"; "produzirá efeitos benéficos", "contribuirão e reforçarão muito para minha formação"; "O Intercâmbio seria uma ótima oportunidade", "contribuiria para minha formação"). Já a coesão nominal foi mantida através do emprego de anáforas e catáforas para se referir a projetos e experiências passados, à universidade em questão, dentre outros.

Analisando ainda os mecanismos de textualização, notamos um grande emprego de conectores. Há os indicadores de objetivo, que introduzem e marcam o objetivo dos candidatos: $a$ fim de, para. Há os conectores aditivos, que valorizam e somam qualidades na construção da imagem ou do argumento: não apenas, mas também; além de. Há os conectores de causa ou justificativa, que introduzem as razões pelas quais os argumentos se sustentam: devido ao; em função de; pois; dessa forma; é por esta razão, visto que. Há também os conectores conclusivos, que finalizam e amarram os argumentos: nesse sentido, assim, portanto, por fim.

Acerca dos mecanismos enunciativos, encontramos evidentemente a voz do próprio candidato, mas também uma voz social do senso comum sobre a aprendizagem e o crescimento 
pessoal da vivência em um país estrangeiro. Essa última voz está implícita nos textos, podendo ser detectada pela compreensão do contexto de produção e dos objetivos implícitos do candidato.

As modalizações constituem uma característica muito peculiar nos planos de estudos, pois elas enfatizam e dão nuance à maneira de se construir a própria imagem. Em todos os textos, encontramos uma alta frequência de modalizações apreciativas, que consistem em uma avaliação do conteúdo temático procedente do mundo subjetivo (enorme, essencial, de suma importância, grandes, benéficos, imensamente) e que, no caso dos textos analisados, apontavam para a experiência do intercâmbio, às experiências já vividas ou às disciplinas a serem cursadas. Outro tipo de modalização encontrado foi a lógica, que consiste em uma avaliação apoiada em nas condições de verdade, fatos atestados ou certos, possíveis, prováveis, eventuais, necessários etc. Essas modalizações estavam ligadas, na maioria das vezes, à própria experiência de intercâmbio (é pertinente; é relevante; é sabido; certamente; é imprescindivel).

As categorias acima analisadas compreendem os elementos passíveis de serem abordados didaticamente a fim de se trabalhar e produzir o gênero plano de estudos e são, portanto, as características ensináveis do gênero. A seguir, proporemos uma sequência didática a ser trabalhada com alunos universitários que desejem eventualmente escrever um plano de estudos.

\section{Uma sequência didática para ensinar a produzir o plano de estudos}

Seguindo a definição de Schneuwly e Dolz (1998; 2004) para a elaboração de sequências didáticas (SD), propomos começar nossa SD pela apresentação da situação de produção; em seguida, pediremos a produção inicial de um plano de estudos, ainda sem ter trabalhado as características do modelo didático. Uma vez analisadas as produções dos alunos, elencaremos quais elementos do gênero precisam ser realmente trabalhados pelo grupo de alunos em questão, elaborando assim um número de módulos (ou aulas) com atividades didáticas voltadas para cada um dos elementos, propondo eventualmente produções intermediárias; e finalmente, pediremos uma produção final de um plano de estudos.

$\mathrm{Na}$ apresentação da situação, começaremos com uma atividade de brainstorming sobre as oportunidades de intercâmbio acadêmico na universidade, observando quais conhecimentos sobre o contexto os alunos já possuem. Em seguida, analisaremos um edital do programa de bolsas, pedindo aos alunos que levantem o conjunto de documentos necessários para a inscrição. Ao falarmos do plano de estudos, perguntaremos aos próprios alunos se já haviam escrito um exemplar desse gênero e que características ele tem. Pediremos, então, uma produção inicial individual.

O primeiro módulo da sequência é dedicado ao estudo do contexto de produção, com atividades sobre o papel social do enunciador, do destinatário e do objetivo do texto. O professor pode se valer dos editais de bolsas, dos objetivos da Vice-Reitoria de Relações Internacionais, dos websites das universidades conveniadas e de um exemplar de um plano de estudos, para identificar quais são os aspectos tipológicos dominantes no texto, por exemplo, narrar, expor, descrever ações, relatar, argumentar (DOLZ, SCHNEUWLY, 2004, p. 41). O objetivo desse módulo é levar o aluno a tomar consciência de que as condições de produção de um texto influenciam sobre seu conteúdo, estilo e estrutura. Uma das atividades didáticas possíveis para esse módulo é a seguinte:

\section{O contexto de produção}

1. Você receberá uma instrução para a redação de um pequeno texto a ser escrito individualmente, de acordo com a situação apresentada. Ao terminar, forme uma dupla com um aluno que tenha um texto diferente. Troquem e leiam os textos, respondendo à pergunta final.

TEXTO A) Escreva um email para um amigo, contando que você vai se inscrever em um intercâmbio acadêmico, explicando o porquê dessa decisão e contando as vantagens disso.

TEXTO B) Escreva um email para um professor da graduação, contando que você vai se inscrever em um intercâmbio acadêmico, explicando o porquê dessa decisão e pedindo que leia seu plano de estudos.

Reflita em grupo: O que muda de um email para o outro com relação à forma ou estrutura do texto? O que muda em relação à linguagem? O que muda em relação aos conteúdos? Por quê?

Quadro 1: Atividade para trabalhar o contexto de produção ${ }^{14}$ 
O segundo módulo é destinado ao trabalho com os conteúdos temáticos e sua organização no texto. Nele, os alunos vão elencar que conteúdos podem e devem constar no plano de estudos, a partir das orientações previstas nos editais e no modelo. É imprescindível retomar os elementos notados no modelo didático, pois eles revelam não somente o que é pedido, mas o que é efetivamente realizado. Uma atividade possível a ser realizada em autonomia seria:

\section{Os conteúdos temáticos}

Ao se apresentar como estudante, você precisa colocar em evidência aspectos acadêmicos.

a) Pense e relacione as atividades acadêmicas que poderiam ser mencionadas em seu plano de estudo.

b) Prepare uma lista de motivos pelos quais você deveria receber uma bolsa de mérito acadêmico. Enumere-os em ordem de relevância.

c) Selecione as disciplinas a cursar na universidade de destino. Explique como cada uma delas contribuirá para sua formação.

Quadro 2: Atividade para trabalhar os conteúdos temáticos ${ }^{15}$

Sistematizados os conteúdos, o professor poderá fornecer um exemplar de um plano de estudos, com trechos fora de ordem e pedir aos alunos que reconstituam o texto, refletindo sobre o que cada ordem possível produz como efeito no destinatário. Os alunos poderão fazer uma produção intermediária, produzindo um plano de estudos a partir de suas próprias informações acadêmicas.

No terceiro módulo, destinado ao trabalho com os mecanismos de textualização, notadamente com os conectores, o professor poderá fornecer um exemplar de um plano de estudos, retirando dele todos os conectores e pedindo que os alunos completem com os conectores que conhecem. Após uma correção conjunta, os alunos terão um arcabouço de conectores possíveis, incluindo sinônimos. Eles deverão, em seguida, classificar os conectores de acordo com sua função ou característica global dentro do texto. Por exemplo: o conector aponta a finalidade dos estudos, introduz uma justificativa etc. A conclusão desse módulo será a reescrita da produção intermediária, inserindo os conectores para ligar os argumentos apresentados e construir uma argumentação favorável à concessão do intercâmbio ou bolsa.

O módulo de número quatro focará o trabalho com os mecanismos enunciativos, sobretudo com as modalizações. O professor poderá fornecer dois exemplares de planos de estudos (ou trechos deles) a serem comparados, um com menos modalizadores e outro com mais. Os alunos deverão primeiramente, na posição de avaliadores de plano de estudos, escolher qual plano de estudos merece ser melhor classificado e justificar. Em seguida, deverão identificar que elementos causam diferença, fazendo um repertório de modalizadores que lhes pareçam úteis e eficazes.
Concluídos os módulos, o professor construirá com os alunos uma grade avaliativa do plano de estudos, contendo os elementos que devem ser encontrados e quais critérios poderiam ser utilizados para a classificação deles. A última etapa da sequência é a produção final, que pode ser avaliada por um dos pares da classe de acordo com a grade construída em conjunto. Caso o professor verifique que ainda há elementos a serem trabalhados, poderá elaborar novos módulos e estender a sequência em função das necessidades do grupo.

\section{Considerações finais}

Observando a ausência de produção científica que aliasse a recente internacionalização das universidades brasileiras e o letramento acadêmico em uma proposta didática, nosso objetivo no presente artigo foi propor um modelo didático do gênero plano de estudos e uma sequência didática para ensiná-lo a alunos universitários. Dentro do quadro teórico do interacionismo sociodiscursivo, apresentamos nossos pressupostos teóricos para o estudo dos gêneros textuais, assim como para o ensino do gênero e para o letramento acadêmico.

Para alcançar nosso objetivo, expusemos a metodologia de trabalho que empregamos através do modelo de análise de textos de Bronckart (1999, 2006). Para chegar ao modelo didático, partimos da análise de textos empíricos e das características que eles apresentam em cada um dos níveis de análise, evidenciando suas características ensináveis. Tal análise nos permite compreender e produzir textos recolocando-os em uma situação de produção e trabalhar elementos linguísticos precisos e 
pertinentes de forma contextualizada. Apresentamos os resultados da análise através da construção do modelo didático do gênero; e, finalmente, propusemos uma sequência didática completa destinada a alunos universitários com o objetivo de pleitear intercâmbio acadêmico.

Sabemos que nosso trabalho apresenta limitações, uma vez que o corpus de textos coletados foi restrito ao número de dez exemplares. Estamos também conscientes da limitação do contexto de amostragem, que foi limitado a somente um programa de bolsas de uma universidade em particular. Entretanto, sendo coerentes com nossa base teórica, entendemos que os gêneros são mutáveis de acordo com as situações de produção e que as capacidades de linguagem trabalhadas em determinado gênero são transferíveis a outros; assim sendo, entendemos que nosso trabalho traz contribuições à comunidade científica, aos estudos linguísticos e, especialmente, aos estudos de letramento acadêmico, na medida em que produzimos conhecimento sobre um gênero recente, pouco conhecido e, atualmente, amplamente demandado.

Finalmente, porém não menos importante, desejamos que este artigo seja útil e relevante do ponto de vista didático, pois o modelo e a sequência didática aqui propostos poderão servir para que professores realizem oficinas de letramento acadêmico e para que estudantes tornem-se candidatos, explorando não somente seu potencial acadêmico, mas suas capacidades de linguagem e, sobretudo, suas capacidades de ação.

\section{Notas}

1 Times Higher Education World University Rankings 2011-2012, acessada em julho de 2013, no endereço: http://www.timeshighereducation. co.uk/world-university-rankings/2013/one-hund red-under-fifty

2 QS World University Rankings 2011, acessada em julho de 2013, no endereço: http:// www.topuniversities.com/university-rankings/w orld-university-rankings/2011

3 Academic Ranking of World Universities 2011, acessada em julho de 2013, no endereço: http://www.shanghairanking.com/ARWU2011.ht $\mathrm{ml}$

4 Conferir: http://www5.usp.br/27130/rankinginternacional-classifica-areas-de-concentracaoda-usp-entre-as-melhores-do-mundo/
5 Conferir: http://www.usp.br/internationaloffice/i ndex.php/programas-e-redes/programas/program a-ciencia-sem-fronteiras/ (acesso em julho de 2013).

6 Angela Kleiman (2006, p. 19) define letramento como "um conjunto de práticas sociais que usam a escrita, enquanto sistema simbólico e enquanto tecnologia, em contextos específicos, para objetivos específicos". Assim, os estudos do letramento têm como objeto de conhecimento os aspectos e os impactos sociais do uso da língua escrita (KLEIMAN, 1995). Dessa forma, consideramos letramento acadêmico as práticas sociais que se valem da escrita no meio acadêmico, sendo objetos de apropriação da esfera universitária.

7 O Laboratório de Letramento Acadêmico funciona desde 2011, auxiliando os alunos que o procuram para acompanhar a elaboração de textos acadêmicos em inglês e francês, porém, a partir de 2013, deverá contar com ajuda para outras línguas, como, por exemplo o alemão e o português. Além disso, um site deverá ser criado para dar maior visibilidade às ações do Laboratório.

8 Outra linha de estudo que se interessa pela mesma problemática diz respeito ao ensino de línguas para fins específicos (MOURLHON-DALLIES, 2008), no caso do inglês o ESP (English for Special Purposes) e, no do francês o FOS (Français sur objectifs spécifiques). Nos dois casos, há vertentes específicas voltadas para o estudo de textos acadêmicos, o English for Academic Purposes (EAP) ou o Français sur Objectifs Universitaires (FOU). Gostaríamos, porém, de estabelecer uma diferença entre as linhas, já que elas advém de quadros epistemológicos distintos. Enquanto nos estudos sobre letramento há uma preocupação com as práticas sociais que fazem uso da língua escrita e com os impactos desta na sociedade (KLEIMAN, 1995), o EAP ou o FOU concentram-se mais em fornecer ferramentas linguísticas (instrumentalizar) para atuação do aluno em contextos específicos, como os profissionais, por exemplo. Existe, portanto, uma clara diferença quanto à função da lingua nas duas linhas teóricas, que não pode ser esquecida.

9 Gostariamos de ressaltar, aqui, a diferença entre a língua enquanto "instrumento psicológico", para Vigotski (2004), que é adquirida pela criança em seu contato com os outros, em ambiente social, 
num processo de internalização e que se torna, posteriormente, uma maneira de agir sobre simesmo, regulando a atividade psíquica, e a noção de língua enquanto instrumento externo, posição de algumas abordagens (sobretudo, no caso do ensino de línguas estrangeiras, a comunicativa ou a de língua para fins específicos), nas quais a língua é vista como exterior au sujeito, que dela faz uso nas situações sociais em que ela é necessária.

10 Para compreender o uso do termo "gênero de textos" ou "gêneros textuais", e não de "gêneros discursivos", conferir Bronckart (2004: 101-103).

11 Os planos de estudo são escritos primeiramente em português e passam por uma primeira apreciação. Em seguida, são escritos em francês e são enviados à universidade em que o aluno pretende estudar.

12 Disponível em:

http://www.ffclrp.usp.br/divulgacao/pesquisa/Pro gramaInternacionaldeBolsas.pdf (acesso em julho de 2013).

13 Página oficial da Vice-Reitoria de Relações Internacionais da USP: http://www.usp.br/intern ationaloffice/index.php/institucional/sobre-a-vrer/ (acesso em julho de 2013).

14 Atividade proposta por Emily Caroline da Silva, como parte integrante do artigo para disciplina "Reflexões e práticas sobre o ensinoaprendizagem de gêneros textuais em língua estrangeira e sobre a produção escrita universitária", ministrada em 2013 pela Profa. Eliane G. Lousada, no Programa de Estudos Linguísticos, Literários e Tradutológicos em Francês da FFLCH-USP.

15 Atividade proposta por Emily Caroline da Silva, como parte integrante do artigo para disciplina "Reflexões e práticas sobre o ensinoaprendizagem de gêneros textuais em língua estrangeira e sobre a produção escrita universitária", ministrada em 2013 pela Profa. Eliane G. Lousada, no Programa de Estudos Linguísticos, Literários e Tradutológicos em Francês da FFLCH-USP.

\section{Referências}

ARAÚJO, Antonia Dilamar. Gêneros Textuais acadêmicos: reflexões sobre metodologias de investigação. In: Rev. de Letras - No. 26 - Vol. 1/2 - jan/dez. 2004.

BAKHTIN, Mikhail. Estética da Criação Verbal. Trad. Paulo Bezerra. São Paulo: Martins Fontes, $1^{\text {a }}$ ed. 1992, $6^{\mathrm{a}}$ ed 2011.

BRONCKART, Jean-Paul. Atividades de linguagem, textos e discursos. São Paulo : EDUC, 1999.

Les genres de textes et leur contribution au développement psychologique. Langages, n. 153, p. 98-108, 2004.

- Atividades de linguagem, discurso e desenvolvimento humano. Mercado de Letras: São Paulo, 2006.

O agir nos discursos: das concepções teóricas às concepções dos trabalhadores. Mercado de Letras: São Paulo, 2008.

Gêneros de textos, tipos de discurso e sequências. Por uma renovação do ensino da produção escrita. In: Letras, Santa Maria, v. 20, n. 40, p. 163-176, jan./jun. 2010.

BUENO, Luzia. Os gêneros jornalísticos e os livros didáticos. Campinas: Mercado de Letras, 2011.

CHEVALLARD, Yves. La transposition didactique - Du savoir savant au savoir enseigné. Grenoble: La Pensée sauvage, 1985 [deuxième édition augmentée 1991].

CRISTOVÃO, Vera Lúcia L. Estudos da linguagem à luz do Interacionismo Sociodiscursivo. Londrina: EDUEL, 2008.

DE PIETRO, Jean-François; SCHNEUWLY, Bernard. O modelo didático do gênero: um conceito da engenharia didática. In: MOARA: revista da pósgraduação em letras da UFPA. Belém: CLA/UFPA, n. 25, jan./jun. 2006, p. 15-52.

DOLZ, Joaquim.; SCHNEUWLY, Bernard. Pour un enseignement de l'oral: initiation aux genres formels à l'école. Paris: ESF, 1998.

DOLZ, Joaquim.; SCHNEUWLY, Bernard. Gêneros e progressão em expressão oral e escrita elementos para reflexões sobre uma experiência suíça (francófona). In: ROJO, Roxane; 
CORDEIRO, Glaís (orgs.) Gêneros orais e escritos na escola. Campinas: Mercado de Letras, 2004, p. 41-70.

FEITOZA, Cláudia de Jesus Abreu. Trabalho docente em EAD: representações construídas em uma entrevista de instrução ao sósia. Dissertação de mestrado, Universidade São Francisco, Itatiba, 2012. Disponível em: http://www.usf.edu.br/itatiba/mestrado/educacao/up loadAddress/EDUCACAO_Claudia[17970].pdf

KLEIMAN, Angela B. Modelos de letramento e as práticas de alfabetização na escola. In:

(Org.). Os significados do letramento: uma nova perspectiva sobre a prática social da escrita [1995]. $9^{a}$ reimpressão. Campinas: Mercado de Letras, 2006, p:15-61.

LOUSADA, Eliane G. Produção Escrita em Francês como Segunda Língua: uma experiência baseada em gêneros textuais. Revista do GEL (Araraquara), v. 6, p. 160-174, 2009.

LOUSADA, Eliane G. Elaboração de material didático para o ensino de francês. In: DIONÍSIO, A. P. ; MACHADO, A. R.; BEZERRA, M. A. (orgs) Gêneros textuais e ensino. São Paulo: Parábola Editora, 2010.

LOUSADA, E. G.; ROCHA, Suélen; GUIMARÃES-SANTOS, Luiza. Gêneros orais, projetos didáticos de gêneros e mobilidade estudantil: perspectivas para ensinar a agir em francês como língua estrangeira. In: BUENO, Luzia; COSTA-HÜBES, Terezinha C. (orgs). Gêneros orais e sua transposição didática. Campinas: Mercado de Letras, 2014.

MACHADO, Anna Rachel; CRISTOVÃO, Vera Lúcia. A construção de modelos didáticos de gêneros: aportes e questionamentos para o ensino de gêneros. In: ABREU-TARDELLI, L. A. CRISTOVÃO, V. L. L. (Orgs). $O$ ensino $e a$ aprendizagem de gêneros textuais. Campinas: Mercado de Letras, 2009. p. 123-151.

MACHADO, Anna Rachel; LOUSADA, Eliane; ABREU-TARDELLI, Lília. Resumo. Coleção Leitura e Produção de textos técnicos e acadêmicos.
São Paulo: Parábola Editorial, 2004a.

Resenha. Coleção Leitura e Produção de textos técnicos e acadêmicos. São Paulo: Parábola Editorial, 2004b.

Planejar gêneros acadêmicos. Coleção Leitura e Produção de textos técnicos e acadêmicos. São Paulo: Parábola Editorial, 2005a.

O Resumo Escolar: Uma Proposta de Ensino do Gênero. In: SIGNUM: Estud. Ling., Londrina, n. 8/1, p. 89-101, jun. 2005b.

Trabalhos de Pesquisa. Coleção Leitura e Produção de textos técnicos e acadêmicos. São Paulo: Parábola Editorial, 2007.

MOTTA-ROTH, Désirée; HENDGES, Graciela Rabuske. Produção textual na universidade. São Paulo: Parábola, 2010.

MOURLHON-DALLIES, Françoise. Enseigner une langue à des fins professionnelles. Paris: Didier, 2008.

NASCIMENTO, Elvira L. Gêneros textuais: da didática das línguas aos objetos de ensino. São Carlos: Claraluz, 2009.

SCHNEUWLY, Bernard. Gêneros e tipos de discurso: considerações psicológicas e ontogenéticas. In: ROJO, Roxane; CORDEIRO, Glaís (orgs.) Gêneros orais e escritos na escola. Campinas: Mercado de Letras, 2004.

SCHNEUWLY, Bernard; DOLZ, Joaquim. Os gêneros escolares. Das práticas de linguagem aos objetos de ensino. In: ROJO, Roxane; CORDEIRO, Glaís (orgs.) Gêneros orais e escritos na escola. Campinas: Mercado de Letras, 2004, p.71-94.

Les genres scolaires: des pratiques scolaires aux objets d'enseignement. Repères, n. 15, p. 27-40, 1997.

Os gêneros escolares. Das práticas de linguagem aos objetos de ensino. In: Revista Brasileira de Educação, $n^{\circ}$ 11, mai-ago, 1999, p.516.

SWALES, John M. Occluded genres in the academy: the case of submission letter. In: 
VENTOLA, E.; MAURANEN, A. (Orgs.). Academic writing: intercultural and textual issues. Amsterdam: John Benjamins, 1996.

VYGOTSKI, Lev S. Pensée et langage. Paris : La dispute, 1997.

\section{Sobre as autoras:}

Emily Caroline da Silva: Mestranda do programa de pós-graduação em Estudos Linguísticos, Literários e Tradutológicos em Francês da Universidade de São Paulo. Atua como professora de francês, assistente de coordenação e formadora profissional dos Cursos Extracurriculares de Francês, da Universidade de São Paulo.

Eliane Gouvêa Lousada:É Mestre (1998) e Doutora (2006) em Lingüística Aplicada e Estudos da Linguagem pela Pontifícia Universidade Católica de São Paulo. É professora do Departamento de Letras Modernas da Faculdade de Filosofia, Letras e Ciências Humanas (FFLCH), área de Estudos Linguísticos, Literários e Tradutológicos em Francês, na Universidade de São Paulo.

Artigo recebido em novembro de 2013

Artigo aprovado em janeiro de 2014
VIGOTSKI, Lev S. Teoria e método em psicologia [1982]. São Paulo: Martins Fontes, 2004.

VOLOCHINOV, Valentin N. Marxismo e filosofia da linguagem [1929]. São Paulo: Hucitec, 2006. 